\title{
Associated Factors and Safety of the Rapidly Achieving First Therapeutic Target of Warfarin in hospitalized Patients: A Retrospective Cohort Study
}

\section{Wenjun Yang}

Zhejiang University School of Medicine Second Affiliated Hospital

Jun Ma

Hangzhou Medical College

Wei Hu

Zhejiang University School of Medicine Second Affiliated Hospital

Haibin Dai

Zhejiang University School of Medicine Second Affiliated Hospital

Huimin Xu ( $\nabla$ xuhuimin78@zju.edu.cn )

Zhejiang University School of Medicine Second Affiliated Hospital

\section{Research Article}

Keywords:

Posted Date: December 17th, 2021

DOI: https://doi.org/10.21203/rs.3.rs-1154876/v1

License: (c) (i) This work is licensed under a Creative Commons Attribution 4.0 International License. Read Full License 


\section{Abstract \\ Background}

Warfarin is a commonly used anticoagulant drug in clinical practice. Rapidly achieving the first therapeutic international normalized ratio (INR) of warfarin may reduce the hospital length of stay. However, little research has been carried out to evaluate the influencing factors and the safety of rapidly achieving the first therapeutic INR target of warfarin.

\section{Aim}

To investigate the associated factors and the safety of rapidly achieving the first therapeutic INR target of warfarin.

\section{Method}

A retrospective cohort study was conducted in inpatients who took warfarin from November 2018 to October 2019. Patients' information was retrieved from medical records.

\section{Results}

487 patients were included. The mean achieving first therapeutic target time was $6.0 \pm 3.2$ days (median, 5.0 days). Age $>65$ years, body mass index $<24 \mathrm{~kg} / \mathrm{m}^{2}$, and initial warfarin dose $\geq 3 \mathrm{mg} / \mathrm{d}$ were independent factors associated with the rapidly achieving first INR target of warfarin therapy. The incidence of INR $\geq 4$ was higher in patients achieving the first INR target rapidly than those achieving the first INR target slowly, while there were no significant differences in bleeding events between the two groups.

\section{Conclusion}

Hospitalized patients aged $>65$ years, with a body mass index $<24 \mathrm{~kg} / \mathrm{m}^{2}$, or receiving an initial warfarin dose $\geq 3 \mathrm{mg} / \mathrm{d}$ were more likely to achieve the first INR target of warfarin rapidly. Closer INR monitoring and appropriate warfarin dose adjustment are recommended to improve the safety for patients achieving the first INR $\geq 1.8$ within 6 days after beginning oral warfarin.

\section{Impacts On Practice}

1. Identifying the factors associated with the rapidly achieving first therapeutic target of warfarin can help physicians appropriately adjust warfarin doses to shorten the patients' time to achieve the 
first therapeutic INR during warfarin treatment.

2. Rapid achievement of first therapeutic INR can reduce post-medication hospital length of stay.

3. Hospitalized patients aged $\leq 65$ years or with a body mass index $\geq 24 \mathrm{~kg} / \mathrm{m}^{2}$ might need a higher initial dose of warfarin to achieve the first INR rapidly after warfarin therapy for the first time.

4. Monitoring INR closer is recommended to ensure the safety of hospitalized patients who achieved the first INR $\geq 1.8$ within 6 days after warfarin therapy for the first time.

\section{Introduction}

Warfarin, the oldest oral anticoagulant, is the most commonly used drug for patients requiring anticoagulant therapy, including primary and secondary prevention of venous thromboembolic disease and thromboembolism in atrial fibrillation, valvular disease, and prosthetic heart valve replacement [1,2]. To achieve an anticoagulant effect, the anticoagulation intensity index-international normalized ratio (INR) of warfarin is required to reach a corresponding target range. Previous studies have shown that rapidly achieving the first therapeutic INR of warfarin may minimize the duration of heparin bridging and potentially decrease the cost of treatment, as well as reduce the hospital length of stay (LOS) [3,4]. However, in clinical practice, it may take several days or even weeks for some inpatients to achieve the first therapeutic INR, and a delay of the achieving first therapeutic INR time may prolong the hospital LOS, increase the risk of cardiovascular events, especially in the initial treatment period [5-7].

Several studies have reported various factors that influence the time to rapidly achieve the first therapeutic INR of warfarin, such as body weight [8], gene [9], disease states [10,11], and warfarin doses $[12,13]$. However, the majority of these studies investigated a single influencing factor on the time to rapidly achieve the therapeutic INR of warfarin, and the results had yielded from various authors. To our knowledge, little research has been carried out to comprehensively assess the multiple factors associated with the rapidly achieving first therapeutic INR of warfarin, and it is still unknown whether rapidly achieving the first therapeutic INR target is safe during warfarin treatment. Based on this, we conducted this study to evaluate the multiple factors related to the rapidly achieving first therapeutic INR target of warfarin therapy and its safety in clinical practice.

\section{Aim}

We aimed to evaluate the demographic and clinical factors that can potentially influence the rapidly achieving first therapeutic INR target of warfarin therapy and its safety in clinical practice.

\section{Ethics approval}

The study protocol was approved by the Medical Ethics Committee of the Second Affiliated Hospital, Zhejiang University School of Medicine on 5 July 2021(NO. 2021-0484).

\section{Methods}




\section{Study design and subjects}

This retrospective cohort study was conducted in inpatients prescribed warfarin from November 2018 to October 2019 at the Second Affiliated Hospital of Medical, Zhejiang University School of Medicine. Using an electronic medical records database, patients' clinical information was collected. The included patients were required to meet the following criteria: (1) aged $\geq 18$ years; (2) new to oral warfarin (without a previous history of warfarin therapy within 1 month before admission); (3) with an INR $\geq 1.8$ before discharge. The exclusion criteria were: (1) patients who changed their anticoagulant medication before discharge and no longer took warfarin; (2) patients with an INR > 1.3 before receiving warfarin; (3) patients who died before discharge.

\section{Data collection and definition}

A chart review was conducted for each patient included in the study. Patients' information was collected, including basic demographics, laboratory data, and clinical data during hospitalization. Demographic data included gender, age, weight, and height. Laboratory data included alanine aminotransferase (ALT), aspartate aminotransferase (AST), total bilirubin, and serum creatinine at baseline of warfarin therapy, as well as dynamic changes of INR during hospitalization. Clinical data included warfarin indications, comorbidities (hypertension, diabetes mellitus, congestive heart failure, stroke, and coronary heart disease), smoking and drinking history, concomitant drugs (e.g., amiodarone; statins such as rosuvastatin, fluvastatin, atorvastatin; antimicrobials such as vancomycin, cefuroxime, cefoperazonesulbactam, and others), the initial warfarin dose, post-medication hospital LOS, and adverse events. Warfarin indications and comorbidities were obtained from patients' admission and discharge diagnoses. Warfarin indications were divided into thrombosis treatment group (valvular heart disease, pulmonary embolism, deep vein thrombosis, and endocardial thrombosis) and thrombosis prophylaxis group (nonvalvular atrial fibrillation and venous thromboembolism prevention). The initial dose of warfarin was divided into low initial dose group ( $<3 \mathrm{mg} / \mathrm{d}$ ) and high initial dose group ( $\geq 3 \mathrm{mg} / \mathrm{d}$ ). Post-medication hospital LOS was defined as the number of days from first warfarin administration to hospital discharge. The body mass index (BMI) was calculated by dividing the weight (in $\mathrm{kg}$ ) by the square of height (in meters). The BMI was divided into a low-BMI group ( $\left.<24 \mathrm{~kg} / \mathrm{m}^{2}\right)$ and a high-BMI group ( $\left.\geq 24 \mathrm{~kg} / \mathrm{m}^{2}\right)$. Liver dysfunction was defined as AST or ALT more than 3 times the upper limit of normal (AST $\geq 102 \mathrm{U} / \mathrm{L}$ or ALT $\geq 132 \mathrm{U} / \mathrm{L}$ ) or total bilirubin more than 2 times the upper limit of normal ( $\geq 52 \mu \mathrm{mol} / \mathrm{L})$ [14]. Severe renal insufficiency (RI) was determined by creatinine clearance $<30 \mathrm{ml} / \mathrm{min}$. Creatinine clearance was calculated by the Cockcroft-Gault equation [140 -age (years)] · weight $(\mathrm{kg}) \cdot(0.85$ if female) / [72 - serum creatinine $(\mathrm{mg} / \mathrm{dl})][15]$.

The achieving first therapeutic target time was defined as the first day reaching the INR threshold of 1.8 following the initiation of warfarin during hospitalization. The patients were divided into slowly achieving the first INR target group ( $>6$ days) and rapidly achieving the first INR target group ( $\leq 6$ days) according to their achieving first therapeutic target time. Adverse events included bleeding events (major or nonmajor bleeding) and laboratory adverse events. Major bleeding was defined as the first fatal or 
symptomatic bleeding event requiring transfusion of at least 2 units of red blood cells or involving a fall in hemoglobin of $\geq 2 \mathrm{~g} / \mathrm{dL}$, or occurring in a critical area (pericardial, intraspinal, intracranial, intraocular, retroperitoneal, intra-articular, or intramuscular with compartment syndrome) [16]. Non-major bleeding was defined as the first bleeding event considered to be clinically relevant non-major or minor bleeding, and not preceded by a major bleeding event [17]. Laboratory adverse event was defined as the first event of inpatients who had an INR of $\geq 4$.

\section{Statistical analysis}

Continuous variables are reported as mean \pm standard deviation or median (interquartile range [IQR]). Categorical variables are reported as numbers (percentage). Significance was determined using Chisquare tests for categorical variables and the Mann-Whitney $U$ tests for non-normally distributed continuous variables. Factors of the rapidly achieving first INR target of warfarin and the low initial warfarin dose were evaluated by univariate analysis and multivariable logistic regression analysis. Baseline characteristics such as age, gender, BMI, smoking and drinking history, warfarin indications, comorbidities, liver and renal dysfunction, concomitant drugs, and an initial warfarin dose were entered into the univariate model. Variables were retained in the final multivariable model if their significance level was $\leq 0.20$ in the univariate analysis. The odds ratio (OR) and corresponding $95 \%$ confidence interval $(\mathrm{Cl})$ were reported for each variable in the model. All statistical analyses were conducted using IBM SPSS Version 23.0. $P<0.05$ was considered statistically significant.

\section{Results}

\section{Patient characteristics}

As shown in Fig. 1, from November 2018 to October 2019, a total of 2,735 inpatients received warfarin, of who 1676 were first-time users. Among patients receiving warfarin for the first time, 961 patients failed to achieve the INR target before discharge, and 1 patient was younger than 18 years of age. Patients who were changed anticoagulants before discharge (39 cases), with INR values $>1.3$ before receiving warfarin (187 cases) and were dead before discharge (1 case), were excluded. Thus, a total of 487 patients were included.

The mean age of the patients enrolled was $60.7 \pm 13.9$ years, and there were 208 female patients (43.7\%). Primary indications for warfarin were valvular heart disease $(66.7 \%)$ and nonvalvular atrial fibrillation (18.3\%). 19 patients (3.9\%) were severe RI, and 37 patients (7.6\%) were liver dysfunction. The mean achieving the first therapeutic target time was $6.0 \pm 3.2$ days (median, 5.0 days [IQR 4-7 days]), with a minimum of 2 days and a maximum of 36 days. The median post-medication hospital LOS was significantly shorter in the rapidly achieving the first INR target group (9 days [IQR 7-12 days]) than in slowly achieving the first INR target group (10 days [IQR 7.5-14 days]) $(P=0.001)$.

\section{Factors associated with the rapidly achieving first INR target of warfarin therapy}


As shown in Table 1, univariate analyses found there were no statistically differences in characteristics such as gender, indications for warfarin, comorbidities (hypertension, congestive heart failure, and coronary heart disease), liver dysfunction, concomitant statins or antimicrobials between the two groups $(P>0.20)$. Other variables with significance $P \leq 0.20$ were retained in the final multivariable model. As shown in Table 2, age $>65$ years (OR 1.761; 95\% Cl 1.138-2.724; $P=0.011), \mathrm{BMI}<24 \mathrm{~kg} / \mathrm{m}^{2}$ (OR 2.040; $95 \% \mathrm{Cl} 1.351-3.079 ; P=0.001)$, and an initial dose of warfarin $\geq 3 \mathrm{mg} / \mathrm{d}(\mathrm{OR} 5.624 ; 95 \% \mathrm{Cl} 2.536-12.473$; $P=0.000$ ) were independent factors associated with the rapidly achieving first INR target of warfarin therapy, severe RI was marginally related to the rapidly achieving first INR target of warfarin therapy (OR 3.787; $95 \% \mathrm{Cl}$ 0.963-14.892; $P=0.057)$. 
Table 1

Patient characteristics for different achieving the first international normalized ratio target groups

\begin{tabular}{|c|c|c|c|}
\hline Variable & $\begin{array}{l}\text { Slowly achieving the first INR } \\
\text { target group }(n=153)\end{array}$ & $\begin{array}{l}\text { Rapidly achieving the first INR } \\
\text { target group }(n=334)\end{array}$ & $P$ \\
\hline Female, n (\%) & $64(31.2)$ & $144(43.1)$ & 0.790 \\
\hline Age > 65 y, n (\%) & $50(32.7)$ & $147(44.0)$ & 0.018 \\
\hline $\begin{array}{l}\text { Body mass index }<24 \\
\mathrm{~kg} / \mathrm{m}^{2}, \mathrm{n}(\%)\end{array}$ & $76(49.7)$ & $225(67.4)$ & 0.000 \\
\hline Smoking history, n (\%) & $36(23.5)$ & $55(16.5)$ & 0.063 \\
\hline Drinking history, n (\%) & $42(27.5)$ & $64(19.2)$ & 0.040 \\
\hline $\begin{array}{l}\text { Indications: Thrombosis } \\
\text { prophylaxis, n (\%) }\end{array}$ & $27(17.6)$ & $64(19.2)$ & 0.691 \\
\hline \multicolumn{4}{|l|}{ Comorbidities, n (\%) } \\
\hline Hypertension & $67(43.8)$ & $156(46.7)$ & 0.549 \\
\hline Diabetes mellitus & $21(13.7)$ & $32(9.5)$ & 0.173 \\
\hline Congestive heart failure & $70(45.7)$ & $154(46.1)$ & 0.942 \\
\hline Stroke & $13(8.5)$ & $42(12.6)$ & 0.187 \\
\hline Coronary heart disease & $22(14.4)$ & $61(18.3)$ & 0.290 \\
\hline Liver dysfunction, n (\%) & $10(6.5)$ & $27(8.1)$ & 0.550 \\
\hline $\begin{array}{l}\text { Severe renal } \\
\text { insufficiency, n (\%) }\end{array}$ & $3(2.0)$ & $16(4.8)$ & 0.134 \\
\hline \multicolumn{4}{|l|}{ Concomitant drugs, n (\%) } \\
\hline Amiodarone & $45(29.4)$ & $122(36.5)$ & 0.125 \\
\hline Statins & $36(23.5)$ & $76(22.7)$ & 0.850 \\
\hline Antimicrobials & $55(35.9)$ & $108(32.3)$ & 0.433 \\
\hline $\begin{array}{l}\text { Initial dose of warfarin } \\
\geq 3 \mathrm{mg} / \mathrm{d}, \mathrm{n}(\%)\end{array}$ & $133(86.9)$ & $319(95.5)$ & 0.001 \\
\hline $\begin{array}{l}\text { Post-medication hospital } \\
\text { length of stay, } d\end{array}$ & $10[7.5-14]$ & 9 [7-12] & 0.001 \\
\hline \multicolumn{4}{|c|}{ Data are presented as $\mathrm{n}(\%)$ or median [IQR]. } \\
\hline $\begin{array}{l}\text { Slowly achieving the first } \\
\text { achieving the first INR tar }\end{array}$ & $\begin{array}{l}\text { target group: the achieving fi } \\
\text { group: the achieving first ther }\end{array}$ & $\begin{array}{l}\text { herapeutic target time }>6 \text { day } \\
\text { dtic target time } \leq 6 \text { days. }\end{array}$ & apidly \\
\hline
\end{tabular}


Table 2

Factors associated with rapidly achieving the first international normalized ratio target of warfarin, multivariable analysis

\begin{tabular}{|lll|}
\hline Variable & OR $(95 \% \mathrm{Cl})$ a & $P$ \\
\hline Age, $>65 \mathrm{y}$ & $1.761(1.138-2.724)$ & 0.011 \\
\hline Body mass index, $<24 \mathrm{~kg} / \mathrm{m}^{2}$ & $2.040(1.351-3.079)$ & 0.001 \\
\hline Smoking history & $0.725(0.421-1.248)$ & 0.246 \\
\hline Drinking history & $0.662(0.395-1.108)$ & 0.116 \\
\hline Diabetes mellitus & $0.563(0.295-1.073)$ & 0.081 \\
\hline Stroke & $1.786(0.891-3.582)$ & 0.102 \\
\hline Severe renal insufficiency & $3.787(0.963-14.892)$ & 0.057 \\
\hline Amiodarone & $1.453(0.939-2.2501)$ & 0.094 \\
\hline Initial dose of warfarin, $\geq 3$ mg/d & $5.624(2.536-12.473)$ & 0.000 \\
\hline Abbreviations: OR, odds ratio; $\mathrm{Cl}$, confidence interval. & & \\
\hline $\begin{array}{l}\text { a Reference groups include age } \leq 65 \mathrm{y}, \mathrm{BMI} \geq 24 \mathrm{~kg} / \mathrm{m}^{2}, \text { no smoking history, no drinking history, no } \\
\text { diabetes mellitus, no severe renal insufficiency, no amiodarone, initial dose of warfarin < 3 mg/d. }\end{array}$ \\
\hline
\end{tabular}

\section{Factors associated with the low initial warfarin dose}

Of the 487 patients, $92.4 \%$ ( 450 cases) of patients' initial warfarin dose were $3 \mathrm{mg}, 7.2 \%$ (35 cases) of patients were initiated with a warfarin dose less than $3 \mathrm{mg}$. Univariate analyses found there were no statistically differences in characteristics such as BMI and comorbidities between the low initial dose group and the high initial dose group $(P>0.20)$, other variables with significance $P \leq 0.20$ were retained in the final multivariable model. As shown in Table 3, four variables were independent factors associated with low initial dose of warfarin, including liver dysfunction (OR 4.057; 95\% $\mathrm{Cl} 1.369-12.022 ; P=0.012$ ), severe RI (OR 4.144; 95\% Cl 1.325-12.956; $P=0.015)$, antimicrobials (OR 2.251; 95\% Cl 1.049-4.831; $P=$ $0.037)$ and thrombosis prophylaxis (OR $3.567 ; 95 \% \mathrm{Cl} 1.483-8.581 ; P=0.005)$. 
Table 3

Factors associated with the low initial dose of warfarin, multivariable analysis

\begin{tabular}{|lll|}
\hline Variable & OR $(95 \% \text { Cl })^{\text {a }}$ & $P$ \\
\hline Female & $2.032(0.897-4.603)$ & 0.089 \\
\hline Age, $>65$ y & $0.975(0.414-2.297)$ & 0.953 \\
\hline Drinking history & $0.170(0.020-1.428)$ & 0.103 \\
\hline Smoking history & $0.637(0.128-3.166)$ & 0.581 \\
\hline Indications: Thrombosis prophylaxis & $3.567(1.483-8.581)$ & 0.005 \\
\hline Liver dysfunction & $4.057(1.369-12.022)$ & 0.012 \\
\hline Severe renal insufficiency & $4.144(1.325-12.956)$ & 0.015 \\
\hline Amiodarone & $0.471(0.194-1.144)$ & 0.096 \\
\hline Statins & $1.613(0.662-3.926)$ & 0.293 \\
\hline Antimicrobials & $2.251(1.049-4.831)$ & 0.037 \\
\hline $\begin{array}{l}\text { a Reference groups include male, age } \leq 65 \text { y, no drinking history, no smoking history, thrombosis } \\
\text { treatment, normal liver function, no severe renal insufficiency, no amiodarone, no statins, no } \\
\text { antimicrobials. }\end{array}$ & \\
\hline
\end{tabular}

\section{Adverse events}

Bleeding events occurred in 68 patients (14.0\%), which were deemed to be non-major. No major bleeding event was recorded in the whole study population. There were no significant differences in bleeding events between the two groups ( $14.7 \%$ vs. $12.4 \%, P>0.05$ ). The incidence of INR $\geq 4$ events occurred in 30 patients $(6.2 \%)$ during hospitalization of warfarin therapy. It was more often in patients achieving the first INR target rapidly than in patients achieving the first INR target slowly $(8.1 \%$ vs. $2.0 \%, P=0.009)$ (Fig. 2).

\section{Discussion}

\section{Statement of key findings}

In the present study, we comprehensively evaluated the multiple factors of the rapidly achieving first therapeutic INR target of warfarin therapy in hospitalized patients. Of note, we demonstrated that patients with age $>65$ years, $\mathrm{BMl}<24 \mathrm{~kg} / \mathrm{m}^{2}$, and initial dose of warfarin $\geq 3 \mathrm{mg} / \mathrm{d}$ were more likely to rapidly achieve the first therapeutic INR target of warfarin, and that rapidly achieving the first INR target significantly reduced the post-medication hospital LOS. Additionally, to the best of our knowledge, this is the first report on the safety of rapidly achieving the first therapeutic INR of warfarin. We revealed that 
rapidly achieving the first therapeutic INR target of warfarin was not associated with a higher risk of bleeding events, whereas increased the incidence of INR $\geq 4$ events.

\section{Strengths and weaknesses}

Our study has a few limitations. First, our study was a retrospective study conducted in one single medical center with a small sample size. Therefore, we could not examine the contribution of all possible influencing factors. Second, genetic factors are known to influence the achieving first therapeutic INR time of warfarin therapy. However, we did not collect enough data due to the limitation of genetic testing in our hospital. Thus, the result of genetic factors was not displayed. But in fact, many hospitals do not conduct genetic testing, doctors often prescribe the initial dose of warfarin based on patients' characteristics, so our findings still have clinical implications.

\section{Interpretation}

The achieving first therapeutic target time was an essential indicator of anticoagulant efficacy $[18,19]$. In our study, the mean achieving first therapeutic target time was $6.0 \pm 3.2$ days (median, 5.0 days), which was slightly shorter than what was reported by most previous assessments $[5,8,20]$. This discrepancy may be mainly due to the relatively lower first therapeutic INR target in our study than other studies (target INR: 1.8 versus 2.0). The target INR of 1.8 was chosen because an INR within $10 \%$ of the lower limit of the therapeutic range of 2.0-3.0 is generally considered the first therapeutic INR achievement of warfarin therapy.

Several factors have been reported to influence the achieving first therapeutic target time during warfarin therapy [8-13]. In this study, we analyzed the potential confounding factors that may contribute to rapidly achieving the first therapeutic INR. Interestingly, we found that patients who rapidly achieved the first therapeutic INR target of warfarin had a lower BMI $\left(<24 \mathrm{~kg} / \mathrm{m}^{2}\right)$. This result was consistent with prior studies $[8,21]$. Consequently, patients with a greater BMI might require a higher warfarin initial dose to achieve the first therapeutic INR earlier. However, BMI has not been taken into account for initial warfarin doses in guidelines. Our result indicated that patients with greater BMI might be given a higher initial dose of warfarin than the routine initial treatment to achieve the first therapeutic INR rapidly.

Besides, we highlighted advanced age ( $>65$ years) as an independent predictor of rapidly achieving the first INR target of warfarin therapy. For this reason, it can be predicted that patients who are aged $\leq 65$ years might need a high initial dose of warfarin to achieve the first INR earlier. Although a few studies showed that age could significantly alter the warfarin maintenance dose requirements to achieve a stable therapeutic INR [22], limited studies investigated the effect of age on the initial dose requirement of warfarin to rapidly achieve the first therapeutic INR. Our study provided evidence that patients aged $\leq 65$ years could begin with warfarin at a high initial dose to shorten the achieving first therapeutic time, thus producing rapid anticoagulant effects.

Like other studies [12,13], the present study showed that a high initial dose of warfarin was an independent predictor of rapidly achieving the first INR target of warfarin therapy. Thus, we further 
analyzed the circumstances under which physicians tended to choose a low initial dose of warfarin and found that patients receiving low initial warfarin doses had more liver dysfunction, severe Rl, concomitant antimicrobials, and indication for thromboprophylaxis, compared with patients receiving high initial warfarin doses. Lower initial doses have been recommended for patients that are elderly, with congestive heart failure or impaired liver function, and those at high risk of bleeding in guidelines $[1,23]$. Our result indicated that the warfarin dosing strategies chosen by Chinese physicians were not entirely recommended by guidelines. However, it is difficult to know which factors still affect the rapidly achieving first INR in this low initial dose of warfarin group, owing to our study's small sample of subgroups.

Notably, our study found that severe RI may be marginally related to the rapidly achieving first INR target of warfarin $(P=0.057)$. A multicenter prospective study found that the achieving first therapeutic time among patients with severe RI was earlier than those without severe RI [24]. Another previous study, involving 1104 patients with nonvalvular atrial fibrillation (NVAF), showed that increased creatinine clearance was an independent factor for the prolonged achieving first therapeutic INR time [20]. Although no statistically significant was observed due to our cohort's small sample size (only 19 patients with severe RI), severe RI might be one of the factors associated with rapidly achieving the first INR target of warfarin therapy.

Other investigated factors such as diabetes mellitus [11], warfarin indications (prosthetic heart valve replacement) [25], cefoperazone-sulbactam [26] have been reported specifically related to the achieving first therapeutic INR time. Notably, in this study, we revealed that factors including gender, smoking and drinking history, comorbidities, warfarin indications, and concomitant medications had no significant effects on the rapidly achieving first therapeutic INR of warfarin therapy. Similar to our study, a prospective observational study [5], involving 1406 outpatients with NVAF, found that gender, smoking history, comorbidities and concomitant medications had insignificant effects on the achieving first therapeutic INR time.

The major complications of warfarin therapy are bleeding and excessive anticoagulation. Thus, we determined the safety of rapidly achieving the first INR after initiation of warfarin treatment, as measured by the incidence of bleeding and INR $\geq 4$ events. Our study found that rapidly achieving the first INR target of warfarin was not associated with a higher risk of bleeding events, whereas increased the incidence of INR $\geq 4$ events. This indicated that the patients who rapidly achieved the first therapeutic INR target of warfarin were more likely to experience an increased risk of supratherapeutic INR. Since there is a strong relationship between the supratherapeutic INR and the risk of bleeding during warfarin treatment [27], it is recommended to closely monitor INR levels in patients rapidly achieving the first therapeutic INR.

\section{Further research}

Based on the result of this study, prospective studies with different initial doses of warfarin in different populations are required to explore the optimal warfarin treatment to rapidly achieve the first therapeutic INR. 


\section{Conclusion}

This study evaluated the influencing factors of the rapidly achieving first therapeutic INR target of warfarin therapy in hospitalized patients and revealed that patients aged $>65$ years, with a $\mathrm{BMI}<24$ $\mathrm{kg} / \mathrm{m}^{2}$, receiving an initial dose of warfarin $\geq 3 \mathrm{mg} / \mathrm{d}$ were more likely to achieve the first therapeutic INR of warfarin rapidly. Patients who were aged $\leq 65$ years, with a BMI $\geq 24 \mathrm{~kg} / \mathrm{m}^{2}$, might need a higher initial dose of warfarin. Closer INR monitoring and appropriate warfarin dose adjustment are recommended to improve the safety for patients achieving the first INR $\geq 1.8$ within 6 days after beginning oral warfarin.

\section{Declarations}

\section{Acknowledgements None}

Funding This study was supported by research grants from the National Natural Science Foundation of China (81703479).

Conflicts of interest The authors have no conflicts of interest to declare.

\section{References}

1. Ageno W, Gallus AS, Wittkowsky A, et al. Oral anticoagulant therapy: Antithrombotic Therapy and Prevention of Thrombosis, 9th ed: American College of Chest Physicians Evidence-Based Clinical Practice Guidelines. Chest. 2012;141(2 Suppl): e44S-e88S.

2. Kearon C, Akl EA, Ornelas J, et al. Antithrombotic Therapy for VTE Disease: CHEST Guideline and Expert Panel Report. Chest. 2016;149(2):315-52.

3. Garcia DA, Baglin TP, Weitz JI, et al. Parenteral anticoagulants: Antithrombotic Therapy and Prevention of Thrombosis, 9th ed: American College of Chest Physicians Evidence-Based Clinical Practice Guidelines. Chest. 2012;141(2 Suppl): e24S-e43S.

4. Godoy LC, Tomlinson G, Abumuamar AM, et al. Association between time to therapeutic INR and length of stay following mechanical heart valve surgery. J Card Surg. 2022; 37(1):629. https://doi.org/10.1111/jocs.16083.

5. Pastori D, Pignatelli P, Cribari F, et al. Time to therapeutic range (TtTR), anticoagulation control, and cardiovascular events in vitamin $\mathrm{K}$ antagonists-naive patients with atrial fibrillation. Am Heart $\mathrm{J}$. 2018;200:32-6.

6. Arendt CJ, Hong JH, Daly RC, et al. Time to achieving therapeutic international normalized ratio increases hospital length of stay after heart valve replacement surgery. Am Heart J. 2017;187:70-7.

7. Dentali F, Pignatelli P, Malato A, et al. Incidence of thromboembolic complications in patients with atrial fibrillation or mechanical heart valves with a subtherapeutic international normalized ratio: a prospective multicenter cohort study. Am J Hematol. 2012;87(4):384-7. 
8. Wallace JL, Reaves AB, Tolley EA, et al. Comparison of initial warfarin response in obese patients versus non-obese patients. J Thromb Thrombolysis. 2013;36(1):96-101.

9. Liu J, Guan H, Zhou L, et al. Impact of gene polymorphism on the initiation and maintenance phases of warfarin therapy in Chinese patients undergoing heart valve replacement. Am J Transl Res. 2019;11(4):2507-15.

10. Sakaan SA, Hudson JQ, Oliphant CS, et al. Evaluation of warfarin dose requirements in patients with chronic kidney disease and end-stage renal disease. Pharmacotherapy. 2014;34(7):695-702.

11. Acar T, Aras YG, Gül SS, et al. Effective INR Level May Be Delayed in Secondary Prevention of Stroke Due to Atrial Fibrillation with Warfarin in the Patients with Diabetes Mellitus. Noro Psikiyatr Ars. 2018;56(4):273-6.

12. Naik D S, Pillai VM, Adole PS. Comparison of 10-mg and 5-mg warfarin initiation nomograms in a South Indian population - An open label trial. Thromb Res. 2019;176:33-5.

13. Farahmand S, Saeedi M, Seyed Javadi HH, et al. High doses of warfarin are more beneficial than its low doses in patients with deep vein thrombosis. Am J Emerg Med. 2011;29(9):1222-6.

14. Temple R. Hy's law: predicting serious hepatotoxicity. Pharmacoepidemiol Drug Saf. 2006;15(4):2413.

15. Xu H, Cai H, Qian Z, et al. Dosing practice of low molecular weight heparins and its efficacy and safety in cardiovascular inpatients: a retrospective study in a Chinese teaching hospital. BMC Cardiovasc Disord. 2012;12:118.

16. Schulman S, Angerås U, Bergqvist D, et al. Subcommittee on Control of Anticoagulation of the Scientific and Standardization Committee of the International Society on Thrombosis and Haemostasis. Definition of major bleeding in clinical investigations of antihemostatic medicinal products in surgical patients. J Thromb Haemost. 2010;8(1):202-4.

17. Bahit MC, Lopes RD, Wojdyla DM, et al. Non-major bleeding with apixaban versus warfarin in patients with atrial fibrillation. Heart. 2017;103(8):623-628. Tellor KB, Nguyen SN, Bultas AC, Armbruster AL, Greenwald NA, Yancey AM. Evaluation of the impact of body mass index on warfarin requirements in hospitalized patients. Ther Adv Cardiovasc Dis. 2018;12(8):207-16.

18. Caraco Y, Blotnick S, Muszkat M. CYP2C9 genotype-guided warfarin prescribing enhances the efficacy and safety of anticoagulation: a prospective randomized controlled study. Clin Pharmacol Ther. 2008;83(3):460-70.

19. Jin H, Jiang F, Wei J, et al. CYP2C9 and VKORC1 genotype-guided individualized warfarin therapy in Chinese patients with acute pulmonary thromboembolism: a randomized controlled clinical study. Int J Clin Exp Med 2017;10(3):5595-602.

20. Lip GYH, Al-Saady N, Jin J, et al. Anticoagulation Control in Warfarin-Treated Patients Undergoing Cardioversion of Atrial Fibrillation (from the Edoxaban Versus Enoxaparin-Warfarin in Patients Undergoing Cardioversion of Atrial Fibrillation Trial). Am J Cardiol. 2017;120(5):792-6.

21. Moffett BS, Bomgaars LR. Response to warfarin therapy in obese pediatric patients dosed according to institutional guidelines. J Pediatr Hematol Oncol. 2014;36(8): e487-9. 
22. Shendre A, Parmar GM, Dillon C, et al. Influence of Age on Warfarin Dose, Anticoagulation Control, and Risk of Hemorrhage. Pharmacotherapy. 2018;38(6):588-96.

23. Hu DY and Sun YH: Chinese Expert Consensus of warfarin anticoagulant therapy. Zhong Hua Nei Ke Za Zhi. 2013;52(1):76-82. (In Chinese)

24. Ning $X$, Kuang $Y$, Yang G, et al. Influence of renal insufficiency on anticoagulant effects and safety of warfarin in Chinese patients: analysis from a randomized controlled trial. Naunyn Schmiedebergs Arch Pharmacol. 2021;394(6):1275-83.

25. Suwanawiboon B, Kongtim P, Chinthammitr Y, et al. The efficacy of 3-mg warfarin initiating dose in adult Thai patients, who required long-term anticoagulant therapy. J Med Assoc Thai. 2011;94 Suppl 1: S225-31.

26. Li B, Liu R, Wang C, et al. Impact of genetic and clinical factors on warfarin therapy in patients early after heart valve replacement surgery. Eur J Clin Pharmacol. 2019;75(12):1685-93.

27. Silva FF, Carvalho JF. Intensity of anticoagulation in the treatment of thrombosis in the antiphospholipid syndrome: a meta-analysis. Rev Bras Reumatol. 2015;55(2):159-66.

\section{Figures}




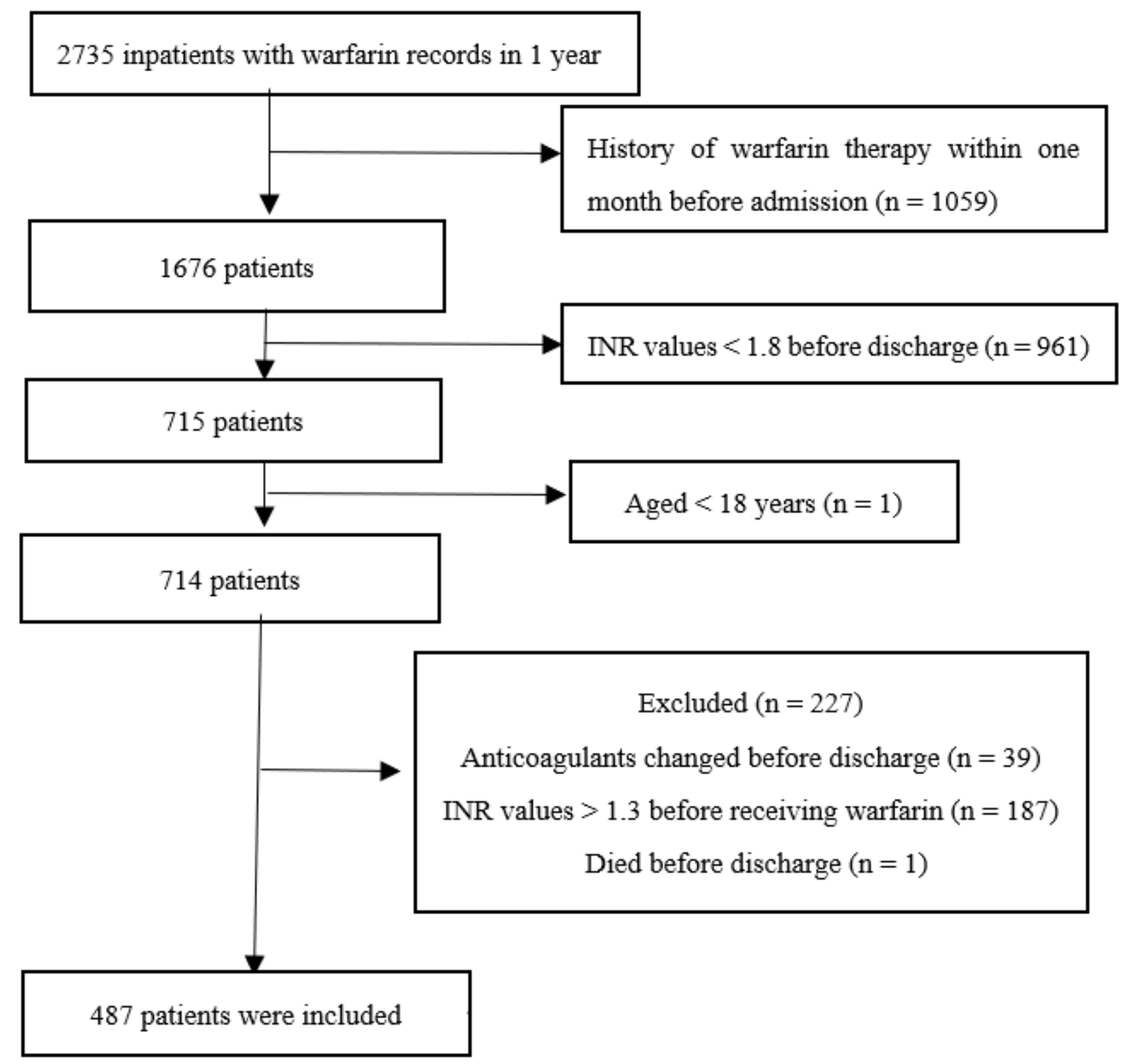

Figure 1

Study population and flow chart. Abbreviations: INR, international normalized ratio. 


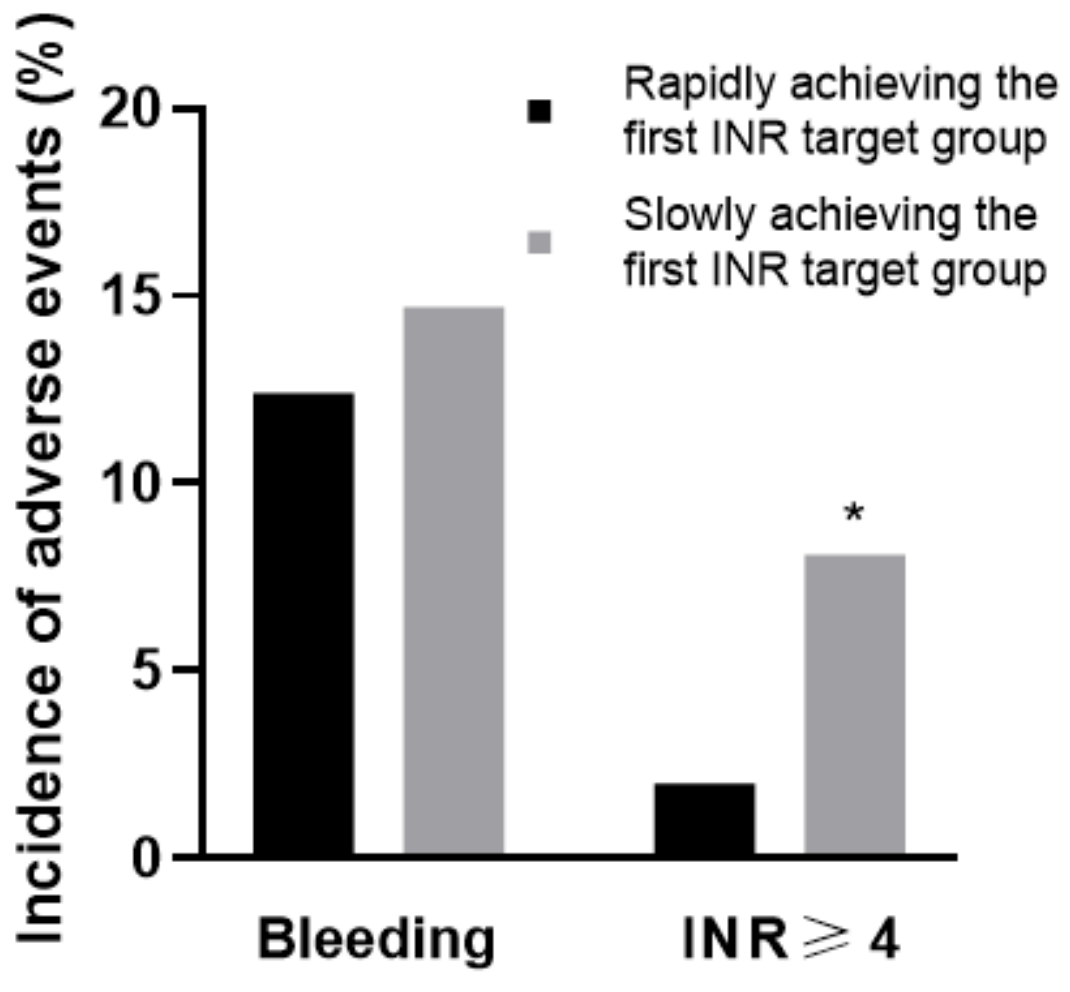

Figure 2

Incidence of bleeding events and international normalized ratio $\geq 4$ events. The incidence of INR $\geq 4$ events was higher in the rapidly achieving the first INR target group than the slowly achieving the first INR target group (8.1\% vs. $2.0 \%)$, * $P<0.01$. 